03

\title{
Распределение температуры на оси камеры расширения при различных схемах работы вихревой трубы
}

\author{
(C) В.Н. Самохвалов \\ Самарский национальный исследовательский университет им. акад. С.П. Королева, Самара, Россия \\ E-mail: vn_samokhvalov@mail.ru
}

Поступило в Редакцию 25 марта 2021 г.

В окончательной редакции 28 июня 2021 г.

Принято к публикации 1 июля 2021 г.

\begin{abstract}
Исследовано изменение температуры воздуха вдоль оси камеры расширения в зонах соплового входа и развихрителя потока в прямоточной, противоточной, трехпоточной и однорасходной вихревых трубах. Установлено, что во всех случаях охлаждение воздуха в вихревой трубе происходит в зоне закручивающего устройства, а его нагрев - в зоне развихрителя потока. Изменение температуры воздуха в осевой зоне по длине камеры расширения происходит за счет теплообмена между зонами нагрева и охлаждения.
\end{abstract}

Ключевые слова: эффект Ранка, вихревые трубки, температурное разделение, теплообмен.

DOI: 10.21883/PJTF.2021.19.51513.18786

Температура на выходах вихревой трубы (BТ) при различных схемах ее работы исследована в $[1,2]$ и ряде других публикаций. В меньшей степени экспериментально исследовано распределение температуры внутри камеры расширения ВТ. Установлено, что при работе противоточной вихревой трубы Ранка-Хилша точка минимальной полной температуры расположена на оси трубы в сечении соплового входного канала, примыкающем к отверстию диафрагмы $[1,3,4]$. С увеличением расстояния от закручивающего устройства радиальный градиент температуры заметно убывает [3]. Профиль избыточной температуры торможения в противоточной вихревой трубе возрастает при приближении к дросселю [1].

Целью экспериментов было исследование распределения температуры воздуха в осевой зоне камеры расширения при различных схемах работы ВТ. В экспериментах использовалось вихревое устройство (рис. 1), в котором переключение режима работы ВТ обеспечивалось установкой заглушек на один или несколько выходных штуцеров (или их удалением) без остановки подачи воздуха на входной штуцер в процессе измерения температуры. Внутренний диаметр цилиндрической камеры расширения вихревой трубы 1 равен $10 \mathrm{~mm}$, длина $76 \mathrm{~mm}$. На фланце 3 выполнен радиальный щелевой развихритель периферийного потока с центральным отверстием. Улитка закручивающего соплового входа 4 (толщиной $2.5 \mathrm{~mm}$ ) профилирована по спирали Архимеда. Зонды 5 и 7 с термопарами TC-K-TYPE-1M (диаметр проводников $0.35 \mathrm{~mm}$ ) плотно установлены в отверстиях штуцеров 6 и 8 , но имеют возможность перемещения вдоль оси камеры расширения. Для минимизации влияния зондов на вихревой процесс рабочие части („капля“') термопар 9 и 10, установленных по оси зондов 5 и 7, выдвинуты относительно торцов зондов на $6 \mathrm{~mm}$. На входной штуцер 11 вихревого устройства из сети сжатого воздуха через редуктор подавалось давление $P=0.15-0.6 \mathrm{MPa}$. Температура воздуха на входе $T_{0}$, внутри вихревой трубы и на выходах 12 и 13 измерялась электронными термометрами Digital Thermometer Mastech MS6500. Величина охлаждения воздуха $\Delta T_{c}=T_{0}-T_{c}$ определялась в зоне закручивающего устройства. Величина нагрева воздуха $\Delta T_{h}=T_{h}-T_{0}$ определялась в зоне развихрителя потока на крышке 3.

В первой серии экспериментов термопара была установлена только в зоне закручивающего устройства (рис. 2,a). Температура измерялась при работе вихревой трубы по трем схемам: трехпоточная ВТ (1), противоточная (2) и прямоточная ВТ (3). При каждом заданном значении давления на входе в вихревое устройство спай термопары перемещался от торца фланца внутрь камеры расширения на величину $L$ (рис. 1$)$. Переключение режимов работы ВТ при каждом фиксированном положении спая термопары производилось без остановки подачи

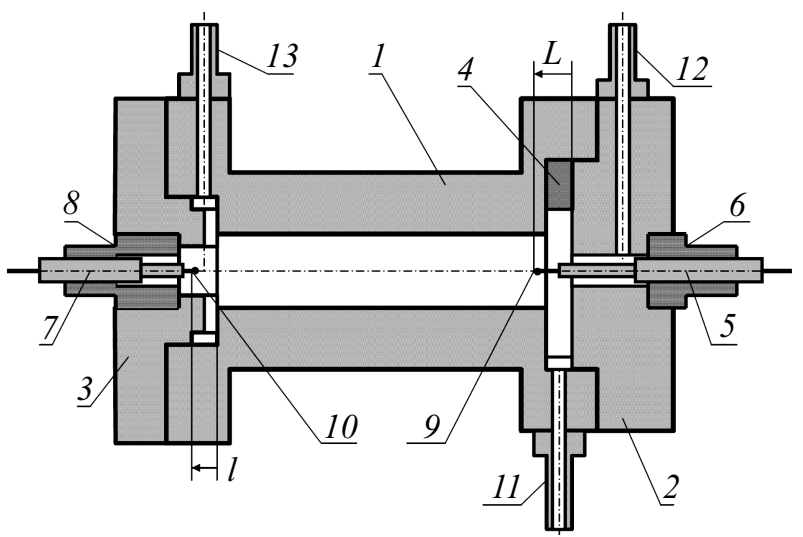

Рис. 1. Принципиальная схема вихревого устройства. Пояснения в тексте. 


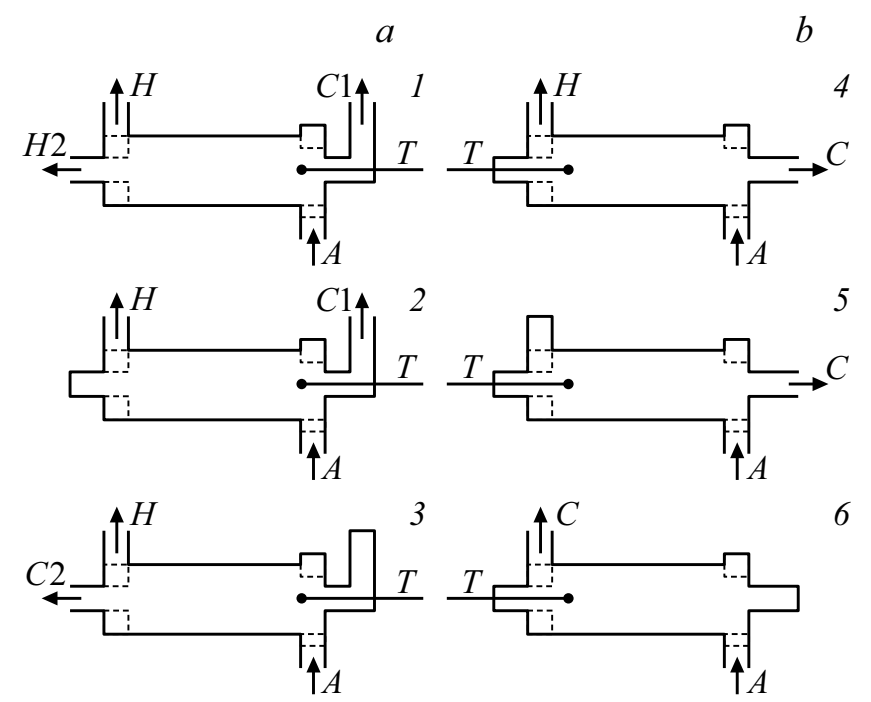

Рис. 2. Схемы работы вихревой трубы. $a-$ первая серия экспериментов: 1 - трехпоточная ВТ, 2 - противоточная ВТ, 3 - прямоточная ВТ; $b-$ вторая серия экспериментов: $4-$ противоточная ВТ, 5 - однорасходная ВТ № $1,6-$ однорасходная ВТ № 2. $A$ - входящий воздух, $C(C 1, C 2)-$ охлажденный воздух, $H$ - подогретый воздух, $T-$ термопара.

воздуха через входной штуцер. Время изменения температуры спая термопары при переключении режимов работы ВТ составляло $1-2 \mathrm{~s}$.

При работе в режиме трехпоточной ВТ (схема 1 на pис. 2,a) при $P=$ const величина охлаждения воздуха $\Delta T_{c}$ практически не изменялась на участке $L=0-9 \mathrm{~mm}$ от диффузора в глубь камеры расширения (кривая 1 на рис. $3, a)$.

При трехпоточном режиме работы ВТ осуществляется осевое течение воздуха через штуцер 8 (рис. 1), что исключает приток подогретого воздуха со стороны развихрителя потока к штуцеру 12. Это обусловливает минимальный теплообмен, и с учетом уменьшения массовой доли воздуха, выходящего через диффузор, обеспечивается большая величина охлаждения воздуха
$\Delta T_{c}$ на оси вихревого устройства в зоне закручивающего устройства. Она больше, чем у прямоточной ВТ (кривая 2 на рис. $3, a)$ и противоточной ВТ (кривая 3 на рис. $3, a)$.

$\mathrm{У}$ противоточной ВТ (схема 2 на рис. 2, $a$ ) обратный приосевой вихревой поток воздуха движется со стороны развихрителя. Величина охлаждения воздуха $\Delta T_{c}$ увеличивается к диффузору при прохождении воздуха через зону закручивающего устройства (кривая 3 на рис. 3,a), что отмечено ранее [1]. Меньшую степень снижения температуры у противоточной ВТ, чем у трехпоточной ВТ, можно объяснить теплопередачей со стороны „горячего“ конца камеры расширения при движении воздуха противоточного вихря. У прямоточной ВТ (схема 3 на рис. 2,a) величина охлаждения воздуха на оси камеры расширения $\Delta T_{c}$ растет за зоной закручивающего устройства $L=2.5-9 \mathrm{~mm}$ (кривая 2 на рис. $3, a$ ). Но при этом снижение температуры охлажденного воздуха на выходе $C 1$ значительно меньше, чем в осевой зоне за закручивающим устройством. Например, при $P=0.5 \mathrm{MPa}$ в точке $L=9 \mathrm{~mm}$ вблизи закручивающего устройства $\Delta T_{c}=35^{\circ} \mathrm{C}$, а на выходе $C 1 \Delta T_{c}$ равна только $14^{\circ} \mathrm{C}$. Это объясняется теплообменом осевых и периферийного слоев в зоне развихрителя потока.

Качественно аналогичные зависимости $\Delta T_{c}$ от $L$ получены для указанных схем работы ВТ во всем исследованном диапазоне давлений на входе в вихревое устройство.

Во второй серии экспериментов зонд с термопарой был установлен в зоне развихрителя потока (рис. 2,b). Спай термопары перемещался вместе с зондом вдоль оси камеры расширения. Величина перемещения $l$ спая термопары измерялась от торца щелевого развихрителя на фланце 3 (рис. 1), положительные значения $l$ - от торца внутрь камеры.

Изменение температуры в зоне развихрителя измерялось при работе вихревой трубы по трем схемам (рис. 2,b): противоточная ВТ (4), однорасходная ВТ № 1 (5), однорасходная ВТ № 2 (6).

При работе устройства в режиме противоточной ВТ (схема 4 на рис. $2, b)$ нагрев осевого слоя воздуха $\Delta T_{h}$ в
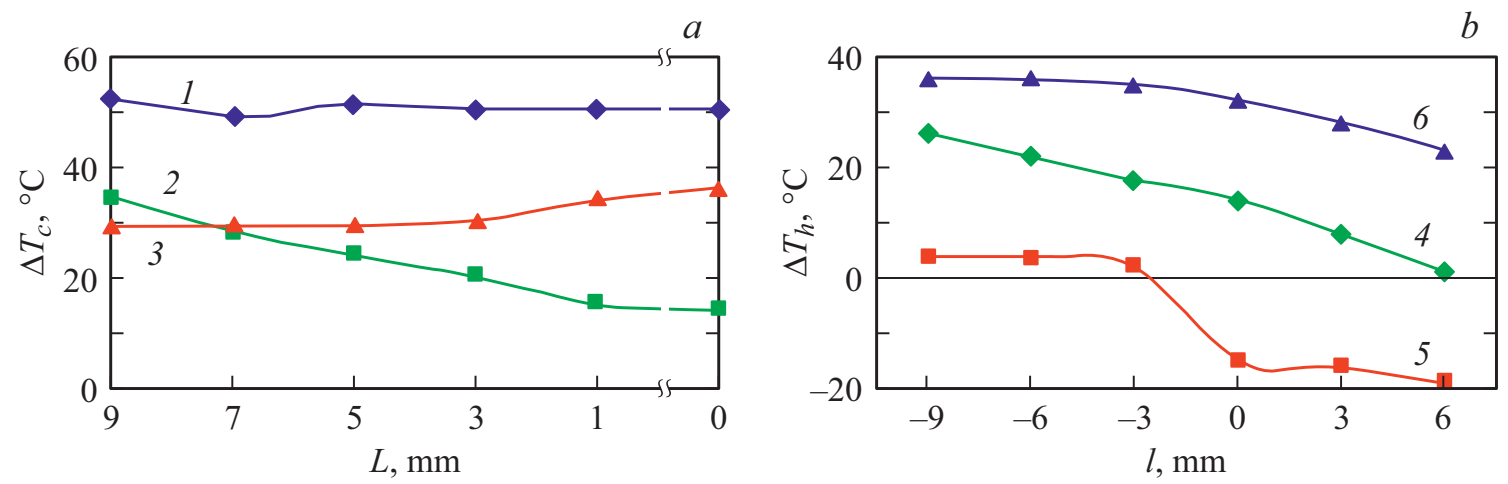

Рис. 3. Изменение температуры на оси вихревой камеры при $P=0.5 \mathrm{MPa} . a-$ в зоне улитки: $1-$ трехпоточная ВТ, $2-$ прямоточная ВТ, 3 - противоточная ВТ; $b-$ в зоне развихрителя: $4-$ противоточная ВТ, $5-$ однорасходная ВТ № 1 , $6-$ однорасходная ВТ № 2. 
камере расширения относительно температуры на входе зафиксирован на расстоянии $l=0-9 \mathrm{~mm}$ от торца развихрителя потока внутри камеры расширения (кривая 4 на рис. $3, b)$. При этом в первой серии экспериментов для противоточной схемы работы ВТ установлено, что в осевой зоне за закручивающим устройством имеет место значительное охлаждение воздуха (кривая 3 на рис. 3,a), т. е. перед развихрителем потока происходит нагрев не только периферийных, но и приосевых слоев воздуха. Величина нагрева увеличивалась при углублении термопары внутрь отверстия в штуцере 8 (рис. 1), т.е. вне зоны вихря. Температура воздуха на выходе $H$ (схема 4 на рис. $2, b)$ равна температуре на оси камеры у торца щелевого развихрителя $(l=0)$.

При работе однорасходной ВТ № 1 (схема 5 на рис. $2, b)$ в зоне развихрителя потока и за ним наблюдался наибольший разогрев осевого слоя воздуха (кривая 5 на рис. $3, b)$. При этом ВТ работала как охладитель воздуха. На выходе $C$ при $P=0.5 \mathrm{MPa}$ охлаждение воздуха $\Delta T_{c}=12-13^{\circ} \mathrm{C}$. При этом происходило охлаждение фланца 2 и корпуса 1 в зоне закручивающего устройства, а также фланца 3 и корпуса 1 (рис. 1).

Таким образом, при отсутствии притока охлажденного воздуха из зоны закручивающего устройства в осевой зоне камеры расширения ВТ у развихрителя потока происходит разогрев воздуха. Это установлено как для противоточной ВТ, так и для однорасходной ВТ № 1 .

При работе однорасходной ВТ № 2 (схема 6 на рис. $2, b)$ охлаждение осевого слоя воздуха зафиксировано до зоны развихрителя потока (кривая 6 на рис. $3, b)$ вследствие притока охлажденного осевого потока из зоны закручивающего устройства. Но величина снижения температуры осевого потока при подходе к развихрителю потока $\left(\Delta T_{c}=15^{\circ} \mathrm{C}\right.$ при $\left.P=0.5 \mathrm{MPa}\right)$ была меньше, чем на оси в камере расширения после закручивающего устройства. Там термопара показывала охлаждение осевого слоя $\Delta T_{c}=30^{\circ} \mathrm{C}$ в точке $L=9 \mathrm{~mm}$, т.е. нагрев осевого потока происходил при его подходе к развихрителю потока. За развихрителем, в отверстии осевого штуцера 8 (рис. 1), наблюдался небольшой разогрев воздуха. Это также свидетельствует об эффекте нагрева воздуха в осевой зоне у развихрителя потока в данном случае, как и при двух других рассмотренных выше режимах работы ВТ.

На выходе $C$ (схема 6 на рис. $2, b$ ) фиксировалось небольшое охлаждение воздуха относительно температуры на входе $A$, т.е. однорасходная ВТ № 2 также работала как охладитель воздуха. Но снижение температуры на выходе $C\left(\Delta T_{c}=4^{\circ} \mathrm{C}\right.$ при $\left.P=0.5 \mathrm{MPa}\right)$ было меньше, чем на оси в камере расширения у торца развихрителя потока $\left(\Delta T_{c}=15^{\circ} \mathrm{C}\right)$, вследствие теплообмена с периферийными слоями воздуха. При этом, как и для однорасходной ВТ № 1, в однорасходной ВТ № 2 также наблюдался разогрев фланца 3 и корпуса 1 в зоне развихрителя потока, одновременно наблюдалось охлаждение фланца 2 и корпуса 1 в зоне закручивающего устройства (рис. 1).
Полученные результаты позволяют сделать вывод, что увеличение охлаждения осевого потока воздуха в вихревой трубе происходит после прохождения прямых или противоточных потоков газа через зону закручивающего устройства независимо от схемы ее работы (прямоточная, противоточная, трехпоточная, однорасходная). Точка минимальной температуры смещается по направлению движения осевого потока воздуха через зону закручивающего устройства. Нагрев воздуха в осевой зоне камеры расширения независимо от схемы работы ВТ происходит в зоне развихрителя потока. Изменение температуры воздуха в осевой зоне по длине камеры расширения происходит за счет теплообмена между зонами нагрева и охлаждения.

\section{Конфликт интересов}

Автор заявляет, что у него нет конфликта интересов.

\section{Список литературы}

[1] Ш.А. Пиралишвили, В.М. Поляев, М.Н. Сергеев, Вихревой эффект. Эксперимент, теория, технические решения (Энергомаш, М., 2000).

[2] T. Dutta, K.P. Sinhamahapatra, S.S. Bandyopadhyay, Int. J. Refrig., 123 (2), 9 (2020).

DOI: $10.1016 /$ j.jirefrig.2020.11.013

[3] М.В. Калашник, К.Н. Вишератин, ЖЭТФ, 133 (4), 935 (2008).

[4] K.N. Visheratin, V.I. Vasiljev, S.M. Kolomiets, A.A. Zarenkov, in Int. Heat Powered Cycles Conf. (Cyprus, 2004), p. 1203. 